Research Article

\title{
Immunohistochemical Studies of Age-Related Changes in Cell Proliferation and Angiogenesis during the Healing of Acetic Acid-Induced Gastric Ulcers in Rats
}

\author{
A. Folorunsho Ajayi $i^{1,2}$ and S. Babafemi Olaleye ${ }^{1}$ \\ ${ }^{1}$ Department of Physiology, College of Medicine, University of Ibadan, Ibadan, Nigeria \\ ${ }^{2}$ Department of Physiology, Ladoke Akintola University of Technology, Ogbomoso, Nigeria \\ Correspondence should be addressed to A. Folorunsho Ajayi; aajayi22@lautech.edu.ng
}

Received 18 November 2019; Accepted 4 May 2020; Published 31 May 2020

Academic Editor: Mustafa Gurhan Ulusoy

Copyright (c) 2020 A. Folorunsho Ajayi and S. Babafemi Olaleye. This is an open access article distributed under the Creative Commons Attribution License, which permits unrestricted use, distribution, and reproduction in any medium, provided the original work is properly cited.

Cell proliferation and angiogenesis are of utmost importance for healing to take place. The KI67 and EGFR proteins are markers of cell proliferation, while CD31 and factor VIII are markers of angiogenesis. To elucidate the mechanism responsible for delayed healing of the gastric injury in old age, we analyzed the expression of these markers in rats of different months during the healing of an acetic acid-induced gastric ulcer. Male Wistar rats (aged 3,6,12, and 18 months) divided into four groups, according to their ages, formed the experimental animals. Stomach tissue samples were collected on days 3, 7, 14, and 21 after induction for assessment of ulcer healing. The area of gastric mucosa healed was inversely proportional to age. The expression of markers of proliferation (KI67 and EGFR) and angiogenesis (factor VIII and CD31) decreased significantly $(p<0.05)$ in older rats when compared with younger ones ( 3 months $>$ six months $>12$ months $>18$ months) on days 7,14 , and 21 after induction of gastric ulcer. This study revealed that the slower gastric ulcer healing rate in older rats might be due to reduced epithelial cell proliferation and angiogenic activities.

\section{Introduction}

Gastric ulcer healing is a genetically determined restoration process which includes inflammation, cell proliferation, reepithelialization, granulation tissue formation, and angiogenesis. The interaction between different cells and the matrix tissue remodelling results in scar formation $[1,2]$. Cytokines control the events above, with the help of various growth factors (epidermal growth factor (EGF), plateletderived growth factor (PDGF), keratinocyte growth factor (KGF), hepatocyte growth factor (HGF), transforming growth factor beta (TGF- $\beta$ ), and vascular endothelial growth factor (VEGF)). The formation of new blood vessels and transcription factors activated by tissue injury in spatial and temporal manner coordinate the healing process [3-5].

The stomach lining can combat damage decreases with age as a result of changes in gastroprotection and decreased mucosal blood flow [6]. Ageing is usually associated with age-linked changes in motor function of the different processes involving the digestive tract, such as transit time and gastric emptying $[7,8]$. The occurrence of digestive diseases increases with age; this corresponds with age-related changes in the structural and functional integrity of the gastrointestinal tract. These changes include mucosa, muscular coat, and blood flow [9-12].

Animal models employed in the study of the role of ageing in gastric mucosal proliferation and regeneration are many. Majumdar and his coworker have reported the higher vulnerability of older rats to acute gastric injury induced with hypertonic saline solution. That proliferative response is more significant in younger rats' gastric mucosa compared to the older ones [13]. Studies on the mechanism of action have shown that ageing is related to reduced regenerative potentials of stomach mucosa damaged by hypertonic saline. The reduction in mucosa regeneration due to age is as a consequence of decreased expression of transforming 
growth factor-alpha. Growth factor receptor such as tyrosine kinases also reduced in expression $[14,15]$ in the stomach mucosa of old rats.

The ability of the stomach mucosa in healthy adult to repair spontaneously after a sudden assault is outstanding. However, the mechanism regulating this repair, as well as the potential modulating effects of ageing, is poorly understood. The modulating fact of ageing on repair processes of gastric mucosa after an injury such as inflammation, cell proliferation, reepithelialization granulation tissue formation, and angiogenesis with regulatory factors, which include growth factors and apoptosis, remains an area of research interest. Therefore, the influence of age in the expression of some molecular factors involved in the healing process of the experimental ulcer was investigated to elucidate the mechanism by which age influences gastric ulcer healing.

\section{Methods}

2.1. Experimental Animals. Eighty male Wistar rats (ages 3, 6,12 , and 18 months) used in the study were bred specially to ascertain their ages, with the parent stock acquired from the Faculty of Basic Medical Sciences Animal House, University of Ibadan, Nigeria. The rats were taken care of in standard cages and were given commercial rat pellets (Ladokun Feeds Limited, Nigeria) with access to water ad libitum. The rats were, after that, separated into four groups according to their ages; each group containing 20 rats. All animals got humane care with the procedures conforming to the guiding principles for research involving animals, recommended by the Declaration of Helsinki together with the Guiding principles in the care and use of animals [16]. The research protocol was submitted to the Ministry of Health, Oyo State, Nigeria, and letter of ethical permission for the conduct of the research was given with reference number: AD 13/479/452. Figure 1 illustrates the graphical representation of the experimental design.
2.2. Acetic Acid-Induced Ulceration. Gastric ulcers were induced using acetic acid following the method described by Tsukimi and Okabe [17] with a little modification. The rats were deprived of feed for 24 hours. The stomach of each rat was exposed under anaesthesia (a mixture of xylazine $(0.0005 \mathrm{ml} / \mathrm{g}$ b.w.) and ketamine $(0.0015 \mathrm{ml} / \mathrm{g}$ b.w. $)$ ) by performing laparotomy through a midline epigastric incision. The stomach glandular walls were clamped with a pair of eye forceps rings, and $0.2 \mathrm{ml}$ of an acetic acid mixture ( $40 \% \mathrm{v} / \mathrm{v}$ distilled water) was injected into the intraluminal secretory area of the stomach and withdrawn after $45 \mathrm{sec}-$ onds. The stomach surface was then bathed with normal saline to prevent tissue adherence, the abdomen were sutured, and rats were allowed to recover. All the animals were fed normally throughout the experimental period with samples collected on days 3, 7, 14, and 21 after induction. We obtain $n=5$, where $n$ is the number of rats involved in a particular experiment.

2.3. Macroscopic Evaluation of Ulcers. Gastric ulcer areas in $\mathrm{mm}^{2}$ were determined on days $3,7,14$, and 21 after induction of ulcer, with five rats taken from each group each day. The rats were sacrificed by cervical dislocation, and the stomach was removed, with the greater curvature opened, washed with normal saline, and pinned on a corkboard. The macroscopic ulcer area was after that measured using a $2 \mathrm{x}$ magnification hand lens, then measured, and calculated using the collection of guiding principles of drug administration of the Ministry of Health Beijing, 1993, as reported by Salami et al. [18] using the following formula:

$$
S=\pi\left(\frac{d 1}{2}\right) \times\left(\frac{d 2}{2}\right),
$$

where $S$ stands for the ulcerated area $\left(\mathrm{mm}^{2}\right), d 1$ represents the longest longitudinal diameter of the ulcer, and $d 2$ is the longest transverse diameter of the ulcer.

The calculation of percentage area of ulcer healed was done as described by Adeniyi et al. [19]:

$$
\begin{gathered}
\text { Percentage area healed on day } 7=\frac{\text { area of an ulcer on day } 3-\text { the area of an ulcer on day } 7}{\text { area of an ulcer on day } 3} \times 100, \\
\text { Percentage area healed on day } 14=\frac{\text { area of an ulcer on day } 3-\text { the area of an ulcer on day } 14}{\text { area of an ulcer on day } 3} \times 100 \text {, }
\end{gathered}
$$

Percentage area healed on day $21=\frac{\text { area of an ulcer on day } 3-\text { the area of an ulcer on day } 21}{\text { area of an ulcer on day } 3} \times 100$

2.4. Sample Processing and Immunohistochemical Analysis. Histological analysis of the sample was carried out as described by Ogihara and Okabe [20]. In brief, small sections of the stomach were taken from two distinct areas of the stomach body (from each rat) and placed in $10 \%$ formalin for histological preparations. The extracted stomach tissue was fixed, cut into five $\mu \mathrm{m}$ sections, and stained with hematoxylin and eosin. Studies involving immunohistochemistry were done using the avidin-biotin peroxidase complex $(\mathrm{ABC})$ in immunoperoxidase techniques by $\mathrm{Hsu}$ et al. [21]. A section of 3 microns of thickness was cut from the paraffin-embedded tissue block and allowed to warm on a hot plate for one hour at $70^{\circ} \mathrm{C}$, followed by deparaffinization of sections in xylene and rehydrating through graded 


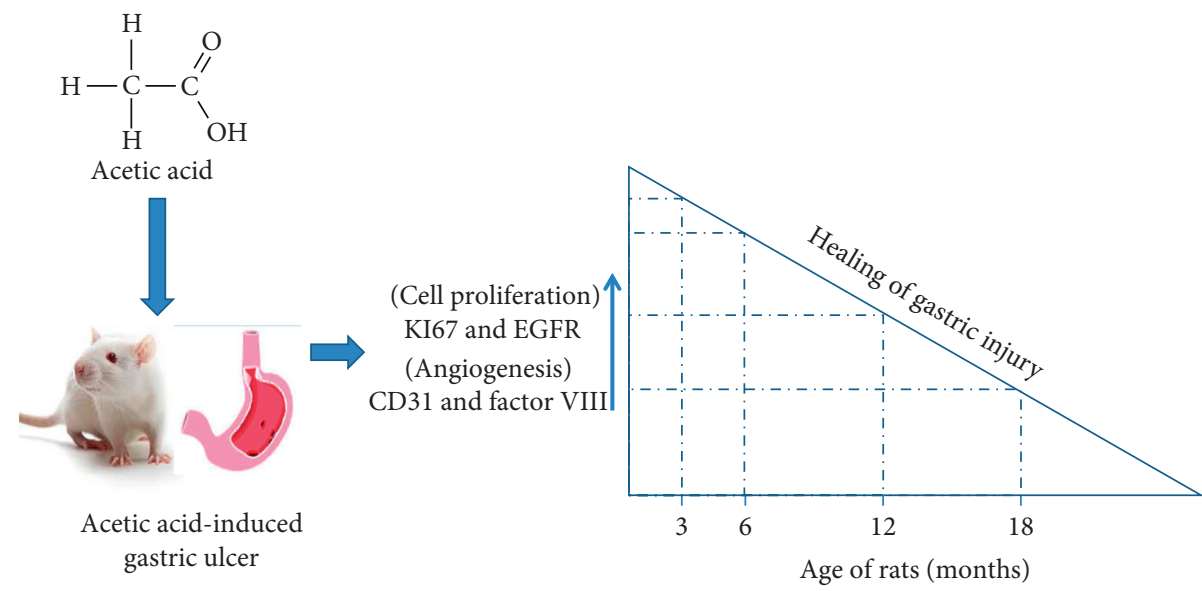

FIgure 1: Graphical abstract.

ethanol to distilled water (i.e., $100 \%, 95 \%, 90 \%$, and $70 \%$ $\mathrm{H}_{2} 0$ ). For antigen retrieval, sections were placed in prewarmed "Target Unmasking Fluid" citric acid solution with pH 6.0 ( $1: 10$ dilution) in a microwave at power 100 for 15 minutes. Then the section is equilibrated by gently displacing in hot citric acid with running tap water for 3 minutes. The peroxidase in tissue was blocked using peroxidase block $\left(0.3 \% \mathrm{H}_{2} \mathrm{O}_{2}\right)$ for 15 minutes and then washed with excess water and stabilized with phosphate-buffered saline (PBS) (in 1-litre distilled water, dissolve $8 \mathrm{~g}$ sodium chloride, $1.44 \mathrm{~g}$ disodium hydrogen phosphate, 0.24 g potassium dihydrogen phosphate, and $0.2 \mathrm{~g}$ potassium chloride. $\mathrm{pH}$ adjusted to 7.4 using HCI) mixed with tween 20 for 2 minutes, and the nonspecific binding proteins were blocked with egg. Avidin protein was blocked in a humidified chamber for 15 minutes and, after that, removed gently by washing for 2 minutes with PBS. Then, the sections were incubated with primary antibodies: anti-rat KI67, EGFR, CD31, and Factor VIII (Novacastro laboratories, United Kingdom) in a humid chamber for 45 minutes, after which it was washed extensively with PBS for 3 minutes. The secondary biotinylated antibody was then used for incubation for 45 minutes at room temperature followed by washing in PBS thrice. A polymer was then added to initiate polymerization, by incubating with streptavidin horseradish peroxidase system (Dako AS, Denmark) for 15 minutes, and then washed twice with PBS. Adding peroxidase substrate DAB for 15 minutes and brown precipitate developed, this indicates positive reaction, which was then washed with water and counterstained for 2 minutes with hematoxylin, followed by dehydration in graded ethanol, and then cleared with xylene, followed by mounting with DPX, and examined under a light microscope at magnification $\times 40$.

2.5. Labelling Index Calculation from ImmunoRatio Web Application. The evaluation of staining intensity and quantity of cells stained by KI67, EGFR, CD31, and factor VIII proteins were evaluated in correspondence to the ulcerated areas. Brown staining of the cytoplasm and nucleus was viewed under $\times 40$ magnification. Positive control slides prepared from cell known to express the protein and control negative slides were made by skipping the incubation state with the primary antibody. The percentages of positively stained nuclei for KI67, EGFR, CD31, and factor VIII were quantified using ImmunoRatio web application (http://jvsmicroscope.uta.fi/immunoratio/) for Image J (http://imagej.nih.gov/ij/). This application resides on a remote server accessed through the Internet with a web browser. The main features include separating diaminobenzidine-stained (DAB) from hematoxylin-stained regions of the image, calculating the percentage of $\mathrm{DAB}$ stained part over the entire region, which is known as the labelling index and generating a pseudo-coloured image corresponding with the area segmentation [22].

2.6. Statistical Analysis. All values are considered as mean \pm SEM (standard error of the mean) in this study, and $n$ stands for the number of rats used for a particular experiment. The statistical significance of differences among the groups was analyzed using one-way ANOVA. Value with $p<0.05$ was considered significant.

\section{Results}

3.1. Macroscopic Evaluation of Ulcers. On the third day, there was no significant difference $(p>0.05)$ between the ulcer areas of 3- and 6-month-old rats, but the 12- and 18-monthold rats' ulcer areas were significantly different from others. Ulcer areas significantly $(p<0.05)$ decreased in younger rats (3 and 6 months old) compared to older ones (12 and 18 months old) on days 7, 14, and 21 after induction as shown in Table 1.

Figure 2 shows that the area of gastric mucosa healed in 3 -month-old rats was significantly $(p<0.05)$ higher than other age groups on days 7 and 14 . On day 21, the threemonth-old gastric mucosa healed utterly (100\%), while 6-, $12-$, and 18 -month-old rats had $94.16 \%, 75.77 \%$, and $69.58 \%$ area of mucosa healed, respectively. 
TABLE 1: Changes in the ulcer area after induction with acetic acid in rats of different ages.

\begin{tabular}{lcccc}
\hline & 3 months & 6 months & 12 months & 18 months \\
\hline Day 3 $\left(\mathrm{mm}^{2}\right)$ & $6.50 \pm 0.21^{\mathrm{a}}$ & $6.70 \pm 0.11^{\mathrm{a}}$ & $9.08 \pm 0.11^{\mathrm{b}}$ & $9.68 \pm 0.27^{\mathrm{c}}$ \\
Day 7 $\left(\mathrm{mm}^{2}\right)$ & $5.26 \pm 0.09^{\mathrm{a}}$ & $5.82 \pm 0.07^{\mathrm{b}}$ & $8.00 \pm 0.06^{\mathrm{c}}$ & $8.64 \pm 0.19^{\mathrm{d}}$ \\
Day 14 $\left(\mathrm{mm}^{2}\right)$ & $1.00 \pm 0.22^{\mathrm{a}}$ & $2.84 \pm 0.27^{\mathrm{b}}$ & $6.32 \pm 0.15^{\mathrm{c}}$ & \\
Day 21 $\left(\mathrm{mm}^{2}\right)$ & $0.00 \pm 0.00^{\mathrm{a}}$ & $0.40 \pm 0.19^{\mathrm{b}}$ & $2.20 \pm 0.12^{\mathrm{c}}$ & \\
\hline
\end{tabular}

Different letters show that figures are statistically different at $p<0.05$.

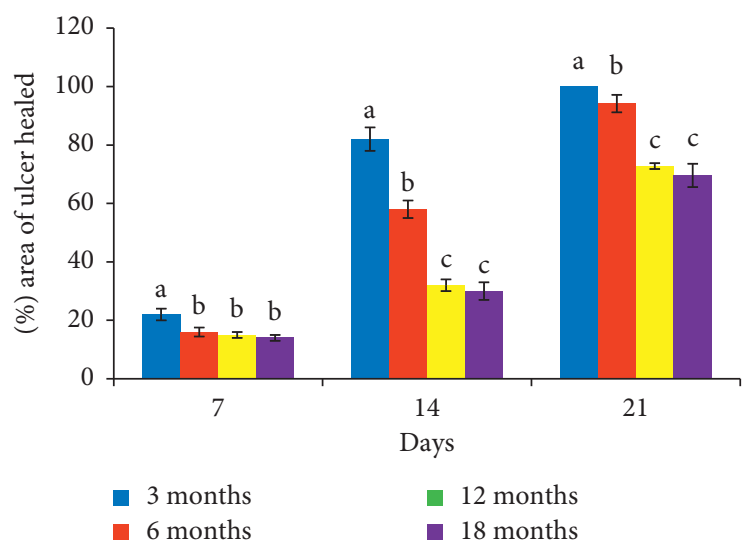

Figure 2: Age-related changes in the area of ulcer healed on days 7, 14, and 21 about day three after induction of ulcer. Bars with letters a, b, and $c$ are statistically different at $p<0.05$.

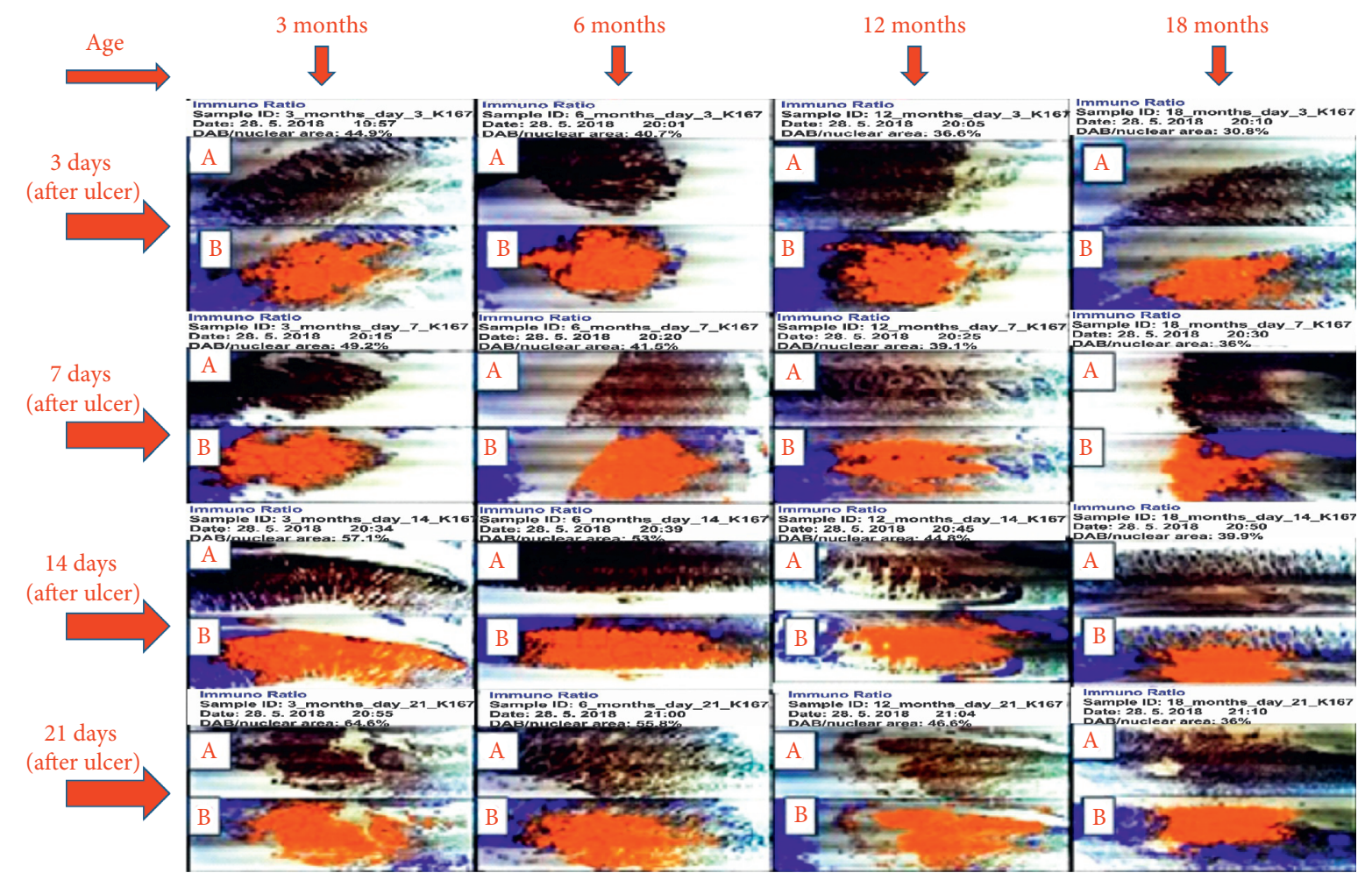

Figure 3: Photomicrograph of expression of KI67 on days 3, 7, 14, and 21 after induction of ulcer. A represents slide of gastric mucosa with original DAB-stained image. B represents slide of gastric mucosa with a pseudo-coloured image produced by ImmunoRatio web application showing staining components from which labelling index ensued. 


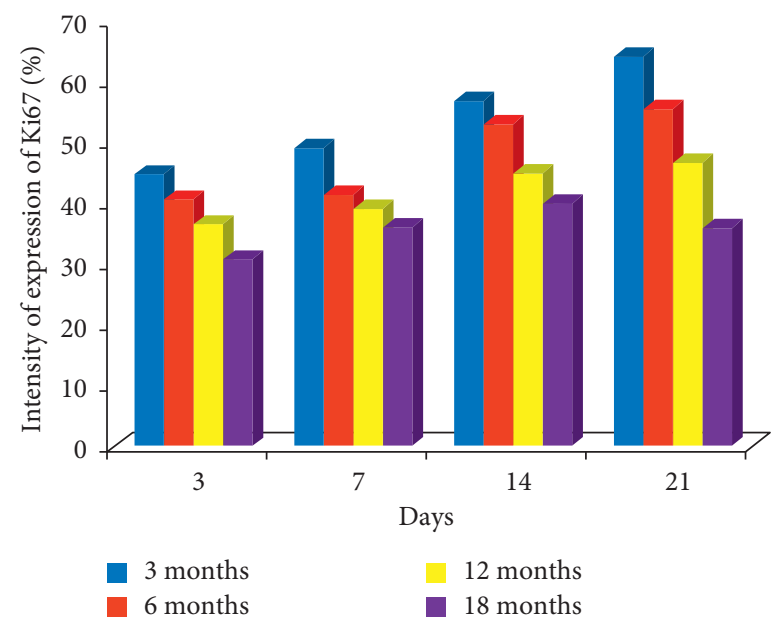

FIGURE 4: Bar chart indicating the age-related changes in the intensity of expression of KI67 on the gastric mucosa during the healing of gastric ulcer induced with acetic acid.

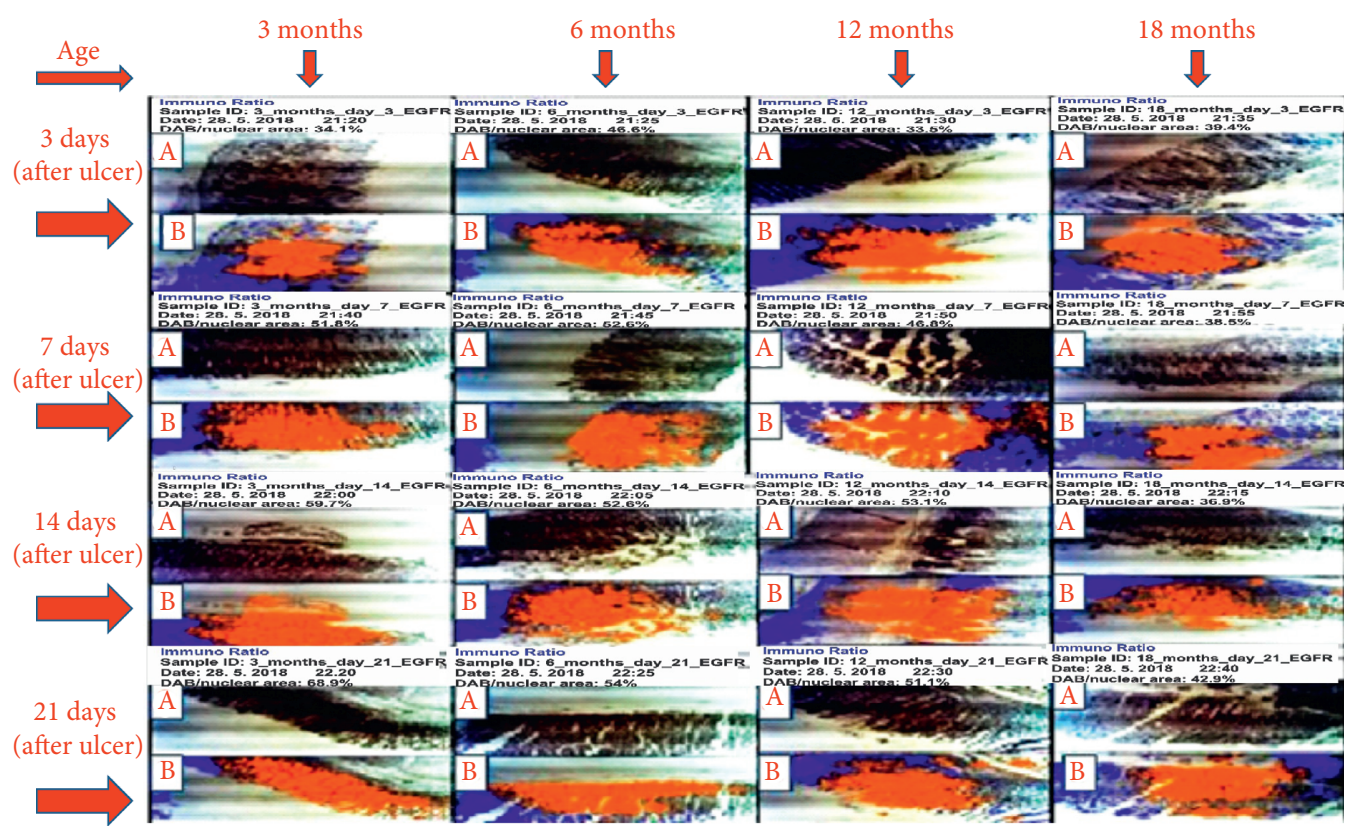

FIGURE 5: Photomicrograph of expression of EGFR on days 3, 7, 14, and 21 after induction of ulcer. A represents slide of gastric mucosa with original DAB-stained image. B represents slide of gastric mucosa with a pseudo-coloured image produced by ImmunoRatio web application showing staining components from which labelling index ensued.

\subsection{Immunohistochemical Studies}

3.2.1. Cell Proliferation. KI67: on day 14, labelling indices of $57.1 \%, 53.0 \%, 44.8 \%$, and $39.9 \%$ were obtained for 3-, 6-, 12-, and 18-month-old rats, respectively. On day 21 , the labelling indices of $64.6 \%, 55.8 \%, 46.6 \%$, and $36.0 \%$ were obtained for 3-, 6-, 12-, and 18-month-old rats, respectively; this means that the highest expression of KI67 was seen in 3-month-old rats during healing as shown in Figures 3 and 4.

EGFR: EGFR showed the same pattern of expression recorded for KI67 on days 14 and 21. On day 14, labelling index of $59.7 \%, 52.6 \%, 53.1 \%$, and $36.9 \%$ ensued for 3-, 6-, $12-$, and 18-month-old rats, respectively. On day 21 , the labelling index of $68.9 \%, 54.0 \%, 51.1 \%$, and $42.9 \%$ was obtained for 3-, 6-, 12-, and 18-month-old rats, respectively, which also suggests that the highest expression of EGFR was seen in 3-month-old rats during healing as shown in Figures 5 and 6 .

3.2.2. Angiogenesis. Factor VIII: the expression of factor VIII was higher in 3-month-old rats than other age categories on days 3, 7, 14, and 21 after induction of ulcer. On day 14 , labelling index of $56.0 \%, 54.6 \%, 47.3 \%$, and $46.7 \%$ was obtained for 3-, 6-, 12-, and 18-month-old rats, respectively. On day 21 , the labelling index of $78.4 \%, 60.7 \%$, $52.1 \%$, and $37.9 \%$ was obtained for 3-, 6-, 12-, and 18month-old rats, respectively, which also suggests that the 


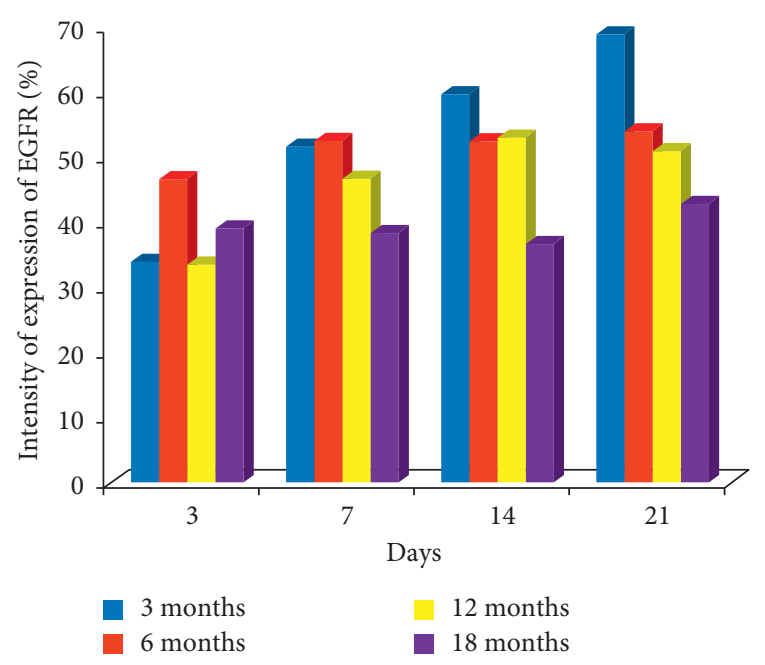

FIGURE 6: Bar chart indicating the age-related changes in the intensity of expression of EGFR on the gastric mucosa during the healing of gastric ulcer induced with acetic acid.

highest expression of factor VIII was seen in 3-month-old rats during healing as shown in Figures 7 and 8.

CD31: the expression of CD31 was higher in 3- and 6month-old rats than 12- and 18-month-old rats on days 3, 7, 14, and 21 after ulcer induction. On day 14, the labelling index of $70.3 \%, 67.5 \%, 52.8 \%$, and $35.3 \%$ was obtained for $6-$, $3-, 12-$, and 18-month-old rats, respectively. On day 21, the labelling index of $69.9 \%, 66.5 \%, 58.6 \%$, and $49.0 \%$ was obtained for 3-, 6-, 12-, and 18-month-old rats, respectively, which also suggests that the highest expression of factor 8 was seen in 3- and 6-month-old rats during healing as shown in Figures 9 and 10.

\section{Discussion}

The results obtained revealed an inverse relationship between age and rate of ulcer healing. Acetic acid ulcer model used in this study produced ulcers of consistent size and severity at an incidence of $100 \%$ and resembled human gastric ulcer in both pathological features and healing mechanism. The slower rate of healing observed in older rats from a macroscopic evaluation of ulcers is consistent with the report from previous work [23].

Healing of gastric ulcer requires reepithelialization as well as potent cell proliferation to fill up mucosal defect and restore gastric glands with the scar $[3,24,25]$. This form of healing is via the proliferation of cells from the ulcer margin and their migration onto the granulation tissue to cover the ulcer base. The poorly differentiated cells from the ulcer margin base sprout into the granulation tissue forming tubules, which transform gastric glands [26, 27].

The protein Ki67 is a biomarker of proliferative activity, which plays a role in ulcer healing; maintaining a dynamic balance between epithelial cell proliferation and apoptosis is essential for maintaining healthy mucosal integrity [28]. Alteration in the balance of epithelial cells proliferation and apoptosis contributes to the formation of gastric ulcer or even carcinogenesis [29, 30]. Therefore, cell proliferation plays a significant role in the healing of gastric ulcers [2, 31]. In this study, Ki67 increased among rats of younger ages (3 and 6 months old) compared with the older rats (12 and 18 months old) during the healing of the acetic acid-induced gastric ulcer. These findings revealed that younger animals have more proliferative activity than older ones during spontaneous healing of the gastric ulcer. Majumdar et al. [13] reported a lower gastric mucosal proliferative response to hypertonic saline-induced acute gastric injury in older rats compared with the younger ones. Subsequent mechanistic studies by Figiel et al. [14] and Relan et al. [15] found out that ageing may be related to diminishing healing capacity of the gastric mucosa that has been damaged by hypertonic saline. Also, this age-related deficiency in mucosa repair is as a result of reduced expression of various growth factors important in the regulation of proliferation (such as transforming growth factor $\alpha$ ) and growth factor receptorrelated enzymes such as tyrosine kinases in the stomachs of aged rats $[14,15]$.

Epidermal growth factor and transforming growth factor-alpha initiate the stimulus for increased epithelial cell proliferation in the mucosa of the ulcer margin [30]. Epidermal growth factor mediates its biological effects on target enterocytes by binding to a specific $170 \mathrm{kDa}$ membranebound glycoprotein receptor, the EGF receptor (EGFR). During the developmental processes of the fetal and adult gastrointestinal tract, liver, and pancreas.

Epidermal growth factor plays an active role [31]. EGFR binding to its receptor activates the intrinsic tyrosine kinase, giving rise to an elaborate cascade of cellular events, which finally results in the synthesis of DNA and cellular growth [32-35]. Healthy mucosal integrity and functions within the gastrointestinal tract are maintained in part by the proliferative activities of EGF [36]. The mechanism involved in the development and progression of the digestive tract injury may be halted by EGF $[37,38]$, or EGF may accelerate the repair process [39]. Studies have shown that administration of epidermal growth factor could protect against both aciddependent gastric assaults $[37,40]$ and independent acid attacks too $[38,40]$; there are records of numerous studies on the role of EGF in gastric ulcer healing [39, 41, 42].

The young and old rats in this study managed EGFR integrity despite the induction of ulcer with acetic acid. However, the three- and six-month-old rats showed increased expression of EGFR compared with the older rats for healing to take place. Nonetheless, previous studies described that the increased expression of EGFR in the epithelial cells of gastric ulcer margins is essential for improving to take place [41]. Also, increased phosphorylation of EGFR resulted in an upsurge of MAP-ERK-1 and ERK-2 kinase phosphorylation levels and actions with more than $440 \%$ and $880 \%$ folds, respectively, at the initial phases of the healing of an experimental gastric ulcer accelerated healing [43]. An increased EGFR expression indicates a vital role of EGF in ulcer healing and scar formation [41, 44].

The development of granulation tissue at ulcer base, new blood vessels formation otherwise called angiogenesis, and restitution of the full glandular architecture of the damaged mucosa may take a few weeks [45]. Angiogenesis is a 


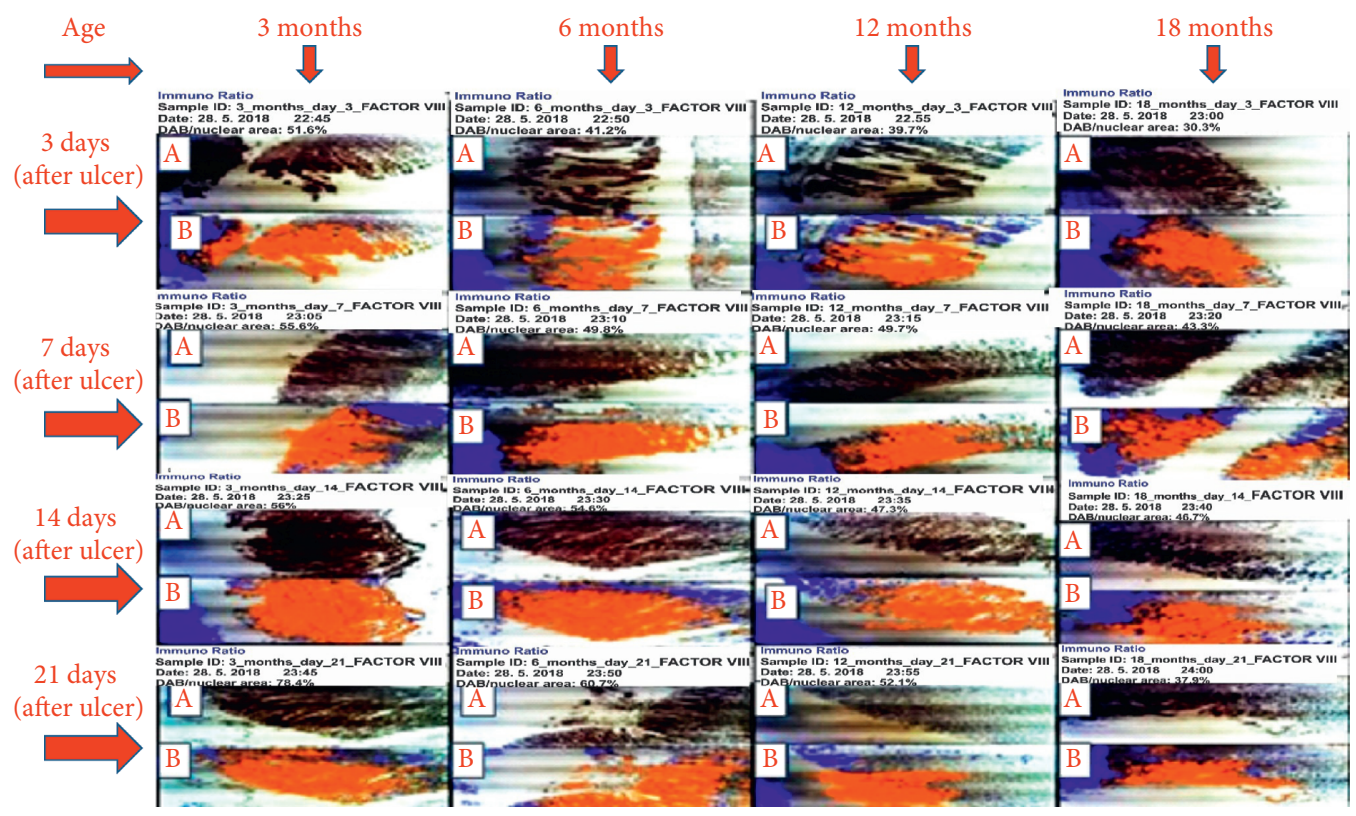

Figure 7: Photomicrograph of expression of factor VIII on days 3, 7, 14, and 21 after induction of ulcer. A represents slide of gastric mucosa with original DAB-stained image. B represents slide of gastric mucosa with a pseudo-coloured image produced by ImmunoRatio web application showing staining components from which labelling index ensued.

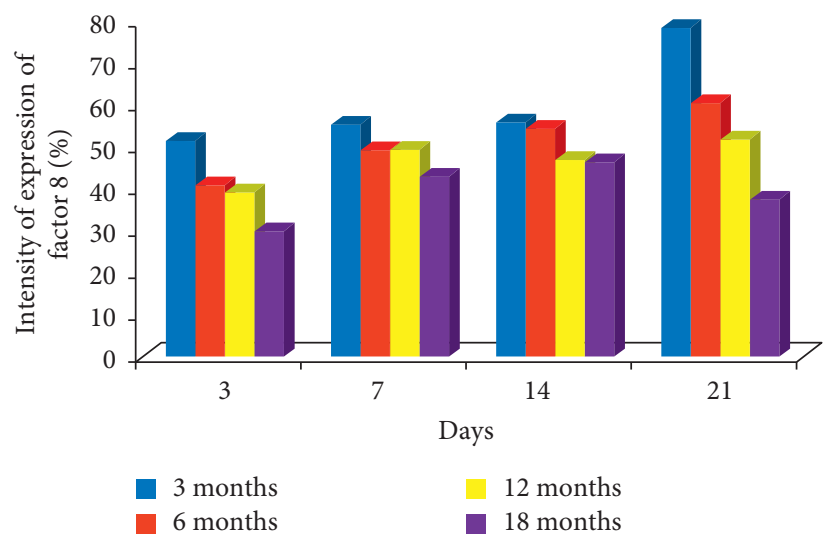

FIgURE 8: Bar chart indicating the age-related changes in the intensity of expression of factor VIII on the gastric mucosa during the healing of gastric ulcer induced with acetic acid.

requirement for the repair of recurring gastroduodenal ulcers $[23,46]$ through the formation a capillary network; angiogenesis in granulation tissue supplies nutrient and oxygen to the base of ulcer thereby facilitating the process of healing $[24,25,47]$. Angiogenesis is essential in the improvement of gastric mucosa healing and prevention of ulcer relapse [24].

Factor VIII is a blood-clotting protein produced by the liver and some epithelial cells; its activation is in response to cellular injury and malignancy [48]. Ulcer base angiogenesis is an essential factor in ulcer healing; several factors are responsible for accelerated angiogenesis which promote healing, and one of such consideration is factor VIII $[49,50]$. In this study, we considered the healing of gastric ulcers induced by acetic acid. There was an increase in the expression of factor VIII in younger rats compared with the older ones, which suggests that the delayed healing seen in old age may be associated with decreased angiogenesis. The result aligns with Amagase et al. [51] reports of reduced angiogenesis in unhealed gastric ulcer.

Platelets endothelial cell adhesion molecule (PECAM1), also known as cluster of differentiation 31 (CD31), is a protein molecule that is involved in leukocyte migration, angiogenesis, and integrin activation [52]. The secretion is by endothelial cells and some epithelial cell and plays a significant role in removing aged neutrophil from the body $[52,53]$. Angiogenesis starts with basement membrane proteolysis [54]. Proteolysis is essential in the induction of microvascular endothelial cell invasion and tube formation. The secretion of proteases requires the activation of both endothelial cells and lymphocytes or monocytes [54]. 


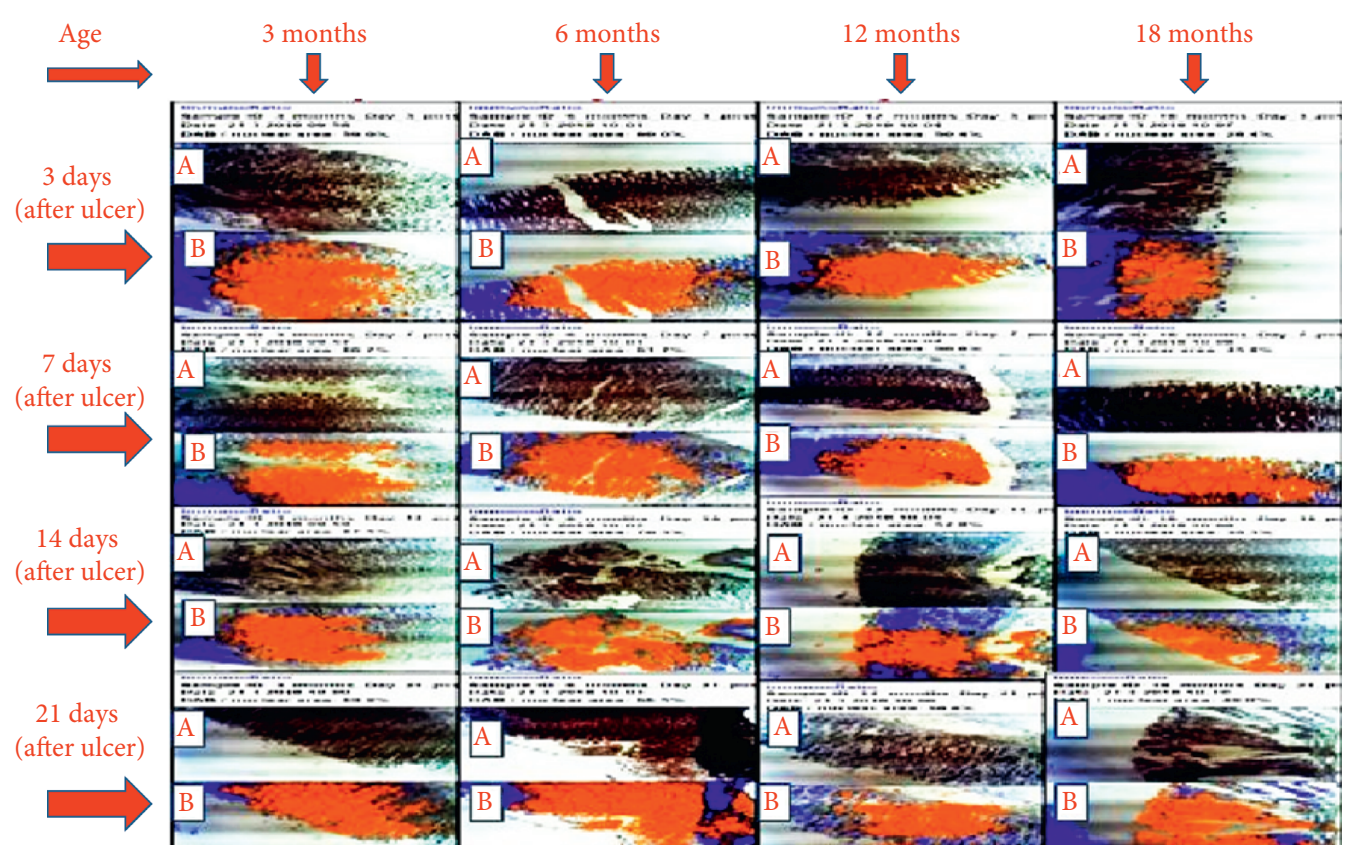

Figure 9: Photomicrograph of expression of CD31 on days 3, 7, 14, and 21 after induction of ulcer. A represents slide of gastric mucosa with original DAB-stained image. B represents slide of gastric mucosa with a pseudo-coloured image produced by ImmunoRatio web application showing staining components from which labelling index ensued.

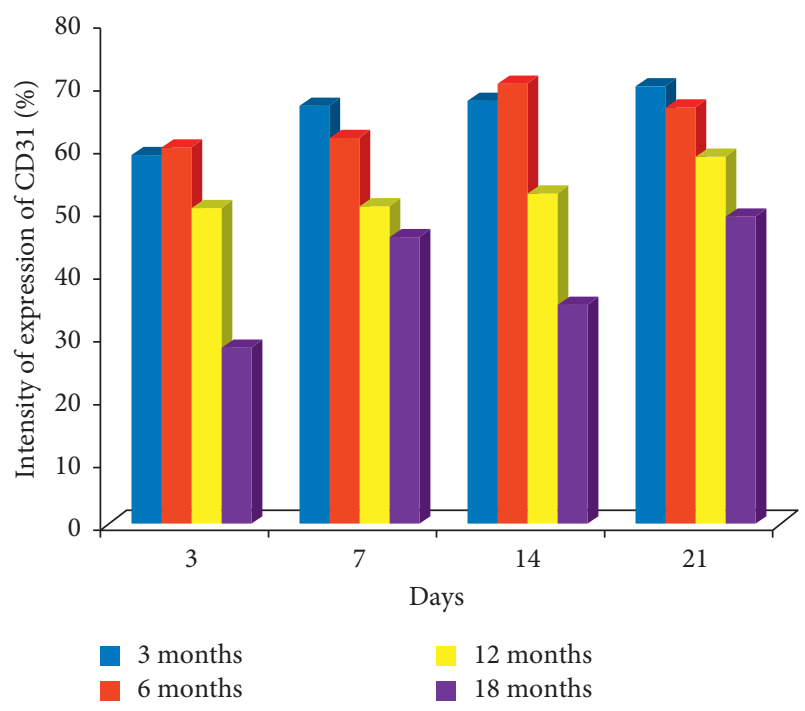

FIgURE 10: Bar chart indicating the age-related changes in the intensity of expression of CD31 on the gastric mucosa during the healing of gastric ulcer induced with acetic acid.

Their activation requires adhesion molecules interaction [55]. Following proteolysis, tube formation occurs, and a series of adhesion molecules come to play a role in tube formation also. Platelet endothelial cell adhesion molecule (PECAM-1/PECAM-1) interplay is responsible for early events of tube formation [55], which results in a tube-like structure formation as a consequence of cell to cell contact. Therefore, antibodies directed against PECAM-1 can inhibit tube formation in vitro [55].

These results showed that there was an overall gradual increase in the activation of angiogenesis by increasing CD31 expression towards healing and CD31 expression decreased with advancing age after induction of ulcer with acetic acid. The role of the formation of new blood vessels in gastroduodenal ulcer healing and its stimulation in granulation tissues significantly accelerate the healing of experimental duodenal ulcer in rats [56]. Also, Skopiñski et al. [57] reported the age-dependence of human serum angiogenic activity. According to Hoenig et al. [58], ageing is related to endothelial dysfunction as well as decreased progenitor cells (EPC) function and mobilization. In this study, higher angiogenic activities occurred in younger rats compared with older ones, which may be due to activation of innate immunity. The activation of a natural immune response is among the first lines of defense after tissue injury [59]. Restoration of blood flow to the site of injured tissue is a prerequisite for mounting an initial immune response to pathogens and for resultant initiation of a successful repair of wounded tissue [59]. Therefore, the innate immunity of younger rats is more potent than that of the older rats, which encouraged increased angiogenic activities in the younger ones and is responsible for the faster healing rate.

\section{Conclusion}

The study shows that the mechanism underlying the slower rate of healing of gastric ulcer with advancing age in rats may be associated with reduced epithelial cell proliferation and angiogenic activities.

\section{Data Availability}

The qualitative and quantitative data used to support the findings of this study are included in the article. 


\section{Conflicts of Interest}

The authors wish to declare that there are no conflicts of interest.

\section{Authors' Contributions}

OSB was responsible for conceptualized and designed the study, AAF did the first draft, and OSB reviewed the first draft.

\section{References}

[1] R. S. Cothran, V. Kumar, and T. Collin's, "Tissue repair, cellular growth, fibrosis, and wound healing," in Robin"s Pathological Basis of Disease, pp. 22-118, W.B. Saunders, Philadelphia, PA, USA, 6th edition, 1999.

[2] A. Tarnawski, "Cellular and molecular mechanisms of gastrointestinal ulcer healing," Digestive Diseases and Sciences, vol. 50, no. 1, pp. S24-S33, 2005.

[3] A. Tarnawski, "Molecular mechanisms of ulcer healing," Drug News \& Perspectives, vol. 13, no. 3, pp. 158-168, 2000.

[4] W.-M. Wong, R. J. Playford, and N. A. Wright, "Peptide gene expression in gastrointestinal mucosal ulceration: ordered sequence or redundancy?" Gut, vol. 46, no. 2, pp. 286-292, 2000.

[5] R. Vanwijck, "Surgical biology of wound healing," Bulletin et memoires de 'Academie royale de medecine de Belgique, vol. 56, pp. 175-184, 2001.

[6] L. Laine, K. Takeuchi, and A. Tarnawski, "Gastric mucosal defense and cytoprotection: bench to bedside," Gastroenterology, vol. 135, no. 1, pp. 41-60, 2008.

[7] A. Saber, "Perioperative care of elderly surgical patients," American Medical Journal, vol. 4, no. 1, pp. 63-77, 2013.

[8] S. Soenen, C. K. Rayner, M. Horowitz, and K. L. Jones, "Gastric emptying in the elderly," Clinics in Geriatric Medicine, vol. 31, no. 3, pp. 339-353, 2015.

[9] I. V. Vilkova, "Structural changes in the stomach muscular coat as a basis for heterochromia in human early postnatal ontogenesis," Morfologiia, vol. 119, no. 3, pp. 80-83, 2001.

[10] M. Ishihara and M. Ito, "Influence of aging on gastric ulcer healing activities of cimetidine and omeprazole," European Journal of Pharmacology, vol. 444, no. 3, pp. 209-215, 2002.

[11] L. M. El-Shall, "Age related changes in the fundic mucosa of stomach of male albino rats (histological and immunohistochemical study)," The Egyptian Journal of Histology, vol. 33, no. 1, pp. 32-44, 2010.

[12] S. Aly and K. B. Emad, "Age-related gastric changes," Journal of Surgery, vol. 4, no. 2, pp. 20-26, 2016.

[13] A. P. N. Majumdar, J. A. Moshier, F. L. Arlow, and G. D. Luk, "Biochemical changes in the gastric mucosa after injury in young and aged rats," Biochim Biophys Acta, vol. 992, pp. 35-40, 1989.

[14] S. E. G. Fligiei, N. K. Relan, S. Dutta, J. Tureaud, J. Hatfield, and A. P. N. Majumdar, "Ageing diminishes gastric mucosal regeneration: relationship to tyrosine kinases," Laboratory Investigations, vol. 70, pp. 764-774, 1994.

[15] N. K. Relan, S. E. G. Fligiel, S. Dutta, J. Tureaud, D. P. Chauhan, and A. P. N. Majumdar, "Induction of EGFreceptor tyrosine kinase, aging and gastric mucosal repair during the early reparative phase of gastric mucosa and effects of ageing," Laboratory Investigation, vol. 73, pp. 717-726, 1995.
[16] World Medical Association and American Physiological Society, "Guiding principles for research involving animals and human beings," American Journal of Physiology-Regulatory, Integrative and Comparative Physiology, vol. 283, pp. R281-3, 2002.

[17] Y. Tsukimi and S. Okabe, "Validity of kissing gastric ulcers induced in rats for the screening of antiulcer drugs," Journal of Gastroenterology and Hepatology, vol. 9, pp. S60-S65, 1994.

[18] A. T. Salami, N. G. Ndukauba, T. O. Iyiola, O. F. Agbola, F. S. Oluwole, and S. B. Olaleye, "Gastroprotective properties of manganese chloride on acetic acid-induced ulcer in wistar rats," African Journal of Biomedical Research, vol. 17, pp. 109-117, 2014.

[19] O. S. Adeniyi, J. Omale, R. I. Egwuje, and O. S. Ajayi, "Effects of selenium treatment on healing of acetic acid-induced gastric ulcer in albino wistar rats," American Journal of Biomedical Science and Research, vol. 4, no. 1, pp. 18-22, 2016.

[20] Y. Ogihara and S. Okabe, "Effect and mechanism of sucralfate on the healing of acetic acid-induced gastric ulcers in rats," Journal of Physiology and Pharmacology, vol. 44, pp. 109-118, 1993.

[21] S. M. Hsu, L. Raine, and H. Fanger, "Use of avidin-biotinperoxidase complex $(\mathrm{ABC})$ in immunoperoxidase techniques: a comparison between $\mathrm{ABC}$ and unlabeled antibody (PAP) procedures," Journal of Histochemistry \& Cytochemistry, vol. 29, no. 4, pp. 577-580, 1981.

[22] A. C. Ruifrok and D. A. Johnston, "Quantification of histochemical staining by colour deconvolution," Analytical and Quantitative Cytology and Histology, vol. 23, pp. 291-299, 2001.

[23] A. F. Ajayi and S. B. Olaleye, "Age-related changes in the response of the rat gastric mucosa to acetic acid- and indomethacin-induced ulceration," Archives of Basic and Applied Medicine, vol. 3, pp. 79-88, 2015.

[24] A. Tarnawski, K. Tanoue, A. M. Santos, and I. J. Sarfeh, "Cellular and molecular mechanisms of gastric ulcer healing. Is the quality of mucosal scar affected by treatment?" Scandinavian Journal of Gastroenterology, vol. 30, no. 210, pp. 9-14, 1995.

[25] A. Tarnawski, I. L. Szabo, S. S. Husain, and B. Soreghan, "Regeneration of gastric mucosa during ulcer healing is triggered by growth factors and signal transduction pathways," Journal of Physiology-Paris, vol. 95, no. 1-6, pp. 337344, 2001.

[26] N. A. Wright, C. Pike, and G. Elia, "Induction of a novel epidermal growth factor-secreting cell lineage by mucosal ulceration in human gastrointestinal stem cells," Nature, vol. 343, no. 2, pp. 82-85, 1990.

[27] D. K. Podolsky, "Peptide growth factors in the gastrointestinal tract," in Physiology of the Digestive Tract, L. R. Johnson, Ed., pp. 129-167, Raven Press, New York, NY, USA, 3rd edition, 1994.

[28] S. F. Moss, J. Calam, B. Agarwal, S. Wang, and P. R. Holt, "Induction of gastric epithelial apoptosis by Helicobacter pylori," Gut, vol. 38, no. 4, pp. 498-501, 1996.

[29] F. Que and G. Gores, "Cell death by apoptosis: basic concepts and disease relevance for the gastroenterologist," Gastroenterology, vol. 110, no. 4, pp. 1238-1243, 1996.

[30] S. F. Moss, "Cellular markers in the precancerous gastric process," Aliment Pharmacol Ther, vol. 12, no. 1, pp. S91-S109, 1998.

[31] H. Xiaoqin, P. Junhua, Z. Hongbin et al., "Enhancement of gastric ulcer healing and angiogenesis by Hepatocyte growth factor gene mediated by attenuated Salmonella in rats," 
Journal of Korean Medical Science, vol. 32, no. 2, pp. 186-194, 2017.

[32] S. S. Poulsen, "On the role of epidermal growth factor in the defence of the gastroduodenal mucosa," Scandinavian Journal of Gastroenterology, vol. 22, no. 128, pp. 20-21, 1987.

[33] M. Forguelafitte, L. Kobari, C. Gespach, M. Chamblier, and G. Rosselin, "Characterization and repartition of epidermal growth factor-urogastrone receptors in gastric glands isolated from young and adult guinea pigs," Biochimica et Biophysica Acta (BBA)_General Subjects, vol. 798, no. 2, pp. 192-198, 1984.

[34] J. A. Barnard, R. Daniel Beauchamp, W. E. Russell, R. N. Dubois, and R. J. Coffey, "Epidermal growth factorrelated peptides and their relevance to gastrointestinal pathophysiology," Gastroenterology, vol. 108, no. 2, pp. 564580, 1995.

[35] W. Ping and W. Zhixiang, "Epidermal growth factor receptor cell proliferation signaling pathways," Cancers, vol. 9, p. 52, 2017.

[36] R. J. Playford and N. A. Wright, "Why is epidermal growth factor present in the gut lumen?" Gut, vol. 38, no. 3, pp. 303-305, 1996.

[37] S. J. Konturek, A. Dembinski, Z. Warzecha, T. Brzozowski, and H. Gregory, "Role of epidermal growth factor in healing of chronic gastroduodenal ulcers in rats," Gastroenterology, vol. 94, no. 6, pp. 1300-1307, 1988.

[38] P. C. Konturek, S. J. Konturek, T. Brzozowski, and H. Ernst, "Epidermal growth factor and transforming growth factor-?: role in protection and healing of gastric mucosal lesions," European Journal of Gastroenterology \& Hepatology, vol. 7, no. 10, pp. 933-938, 1995.

[39] P. S. Olsen, S. S. Poulsen, K. Therkelsen, and E. Nexo, "Effect of sialoadenectomy and synthetic human urogastrone on healing of chronic gastric ulcers in rats," Gut, vol. 27, no. 12, pp. 1443-1449, 1986.

[40] S. J. Konturek, T. Brzozowski, J. Majka, A. Dembinski, A. Slomiany, and B. L. Slomiany, "Transforming growth factor alpha and epidermal growth factor in protection and healing of gastric mucosal injury," Scandinavian Journal of Gastroenterology, vol. 27, no. 8, pp. 649-655, 1992.

[41] A. Tarnawski, J. Stachura, T. Durbin, I. J. Sarfeh, and H. Gergely, "Increased expression of epidermal growth factor receptor during gastric ulcer healing in rats," Gastroenterology, vol. 102, no. 2, pp. 695-698, 1992.

[42] M. R. Alison, R. Chinery, R. Poulsom, P. Ashwood, J. M. Longcroft, and N. A. Wright, "Experimental ulceration leads to sequential expression of spasmolytic polypeptide, intestinal trefoil factor, epidermal growth factor and transforming growth factor alpha mRNAs in rat stomach," The Journal of Pathology, vol. 175, no. 4, pp. 405-414, 1995.

[43] R. Pai, M. Ohta, R. M. Itani, I. J. Sarfeh, and A. S. Tarnawski, "Induction of mitogen-activated protein kinase signal transduction pathway during gastric ulcer healing in rats," Gastroenterology, vol. 114, no. 4, pp. 706-713, 1998.

[44] M. Yurtçu and Z. F. Baba, "The effect of epidermal growth factor applied locally for pelvis-ureteral anastomoses," International Journal of Clinical and Experimental Medicine, vol. 7, pp. 4226-4231, 2014.

[45] J. L. Wallace and P. R. Devchand, "Emerging roles for cyclooxygenase-2 in gastrointestinal mucosal defense," British Journal of Pharmacology, vol. 145, no. 3, pp. 275-282, 2005.

[46] G. Khoder, A. A. Al-Menhali, F. Al-Yassir, and S. M. Karam, "Potential role of probiotics in the management of gastric ulcer," Experimental and Therapeutic Medicine, vol. 12, no. 1, pp. 3-17, 2016.

[47] A. Tarnawski, "Cellular mechanisms of gastric ulcer healing," in The Stomach, W. Domschke and S. J. Konturek, Eds., pp. 177-192, Springer, Berlin, Germany, 1993.

[48] V. R. Arruda, "The search for the origin of factor VIII synthesis and its impact on therapeutic strategies for hemophilia A," Haematologica, vol. 100, no. 7, pp. 849-850, 2015.

[49] S. Hase, S. Nakazawa, Y. Tsukamoto, and K. Segawa, "Effects of prednisolone and human epidermal growth factor on angiogenesis in granulation tissue of gastric ulcer induced by acetic acid," Digestion, vol. 42, no. 3, pp. 135-142, 1989.

[50] U. A. Okonkwo and L. A. DiPietro, "Diabetes and wound angiogenesis," International Journal of Molecular Sciences, vol. 18, no. 7, p. E1419, 2017.

[51] K. Amagase, M. Yokota, S. Tsukimi, and S. Okabe, "Characterisation of "unhealed gastric ulcer" produced with chronic exposure of acetic acid ulcer to indomethacin in rats," Journal of Physiology and Pharmacology, vol. 54, no. 3, pp. 249-360, 2003.

[52] R. J. Gumina, N. E. Kirschbaum, P. N. Rao, P. VanTuinen, and P. J. Newman, "The human PECAM1 gene maps to 17q23," Genomics, vol. 34, no. 2, pp. 229-232, 1996.

[53] P. Newman, M. Berndt, J. Gorski et al., "PECAM-1 (CD31) cloning and relation to adhesion molecules of the immunoglobulin gene superfamily," Science, vol. 247, no. 4947, pp. 1219-1222, 1990.

[54] D. Hanahan and J. Folkman, "Patterns and emerging mechanisms of the angiogenic switch during tumorigenesis," Cell, vol. 86, no. 3, pp. 353-364, 1996.

[55] J. A. Madri, L. Bell, and J. R. Merwin, "Modulation of vascular cell behavior by transforming growth factors?" Molecular Reproduction and Development, vol. 32, no. 2, pp. 121-126, 1992.

[56] J. Folkman, S. Szabo, M. Stovroff, P. McNeil, W. Li, and Y. Shing, "Discovery of a new mechanism and development of angiogenic therapy that accelerates healing," Annals of Surgery, vol. 214, no. 4, pp. 414-427, 1991.

[57] P. Skopiñski, E. Skopiñska-Rózewska, and L. Jung, "Age dependence of the angiogenic activity of human serum," Central European Journal of Immunology, vol. 34, pp. 53-57, 2009.

[58] M. Hoenig, C. Bianchi, A. Rosenzweig, and F. Sellke, "Decreased vascular repair and neovascularization with ageing: mechanisms and clinical relevance with an emphasis on hypoxia- inducible factor-1," Current Molecular Medicine, vol. 8, no. 8, pp. 754-767, 2008.

[59] F. Stefan, A. V. Karen, F. Olivier, and A. K. Ralph, "Innate immunity and angiogenesis," Circulation Research, vol. 96, pp. 15-26, 2005. 